\title{
EL LUGAR Y LA FÓRMULA: “CUBO DE KÉPLER”, DE BERNARDO SCHIAVETTA, UN LABERINTO POÉTICO CONTEMPORÁNEO
}

\author{
Daniel Mesa Gancedo \\ Universidad de Zaragoza
}

La escritura de pocmas laberínticos en la actualidad tiene que ver básicamente con dos líneas de desarrollo de la poesía en la postmodernidad, análogas, pero no necesariamente solidarias: por un lado, la poesía visual heredera del caligrama. Explorar esta tendencia llevaría muy lejos por el camino de las relaciones actuales entre palabra e imagen y obligaría a internarnos incluso en el arte cibernético'. No todos los poemas visuales, obviamente, son laberintos que cumplan la condición de posibilitar una lectura "en múltiples sentidos", pero por lo general los laberintos suelen ser admitidos sin demasiada dificultad como poemas visuales. En segundo lugar, la escritura laberíntica en la actualidad se relaciona, necesariamente, con la poesía escrita bajo "constricciones" (como traducción del término contrainte, cimiento de gran parte de la actividad del OULIPO francés ${ }^{2}$ ). Este último término, entendido como regla generadora (y, al tiempo, descifradora) de un texto dado, va a ser fundamental para entender Fórmulas para Cratilo, el libro de Bernardo Schiavetta que incluye cl "Cubo de Képler" (Fig. 1). Pero hay que insistir en que el laberinto poético actual es una función de ambas escrituras: visual y "constricta".

1.- Para el ámbito español es esencial Cózar (1991), actualizable con las cada vez más abundantes referencias en internet. El estudio más extenso y abarcador del que tengo noticia para el ámbito hispanoamericano es el de Clemente Padín (2001).

2.- Los ejemplos más habituales de "constricciones" en el marco del OULIPO son muy conocidos: el S+7, el lipograma, diversos juegos combinatorios, etc. I a bibliografía sobre el OULIPO es ya abundantísima: una contribución española es Altarriba, ed. (1987); una reciente puesta al día, en el número especial de Magazine Littéraire, 398, mayo, 2001.

3.- Cito por la única edición disponible (Schiavetta, 1990a), dando sólo el número de página. El libro recibió el III premio Loewe de poesía en 1990, otorgado por un jurado presidido por Octavio Paz. Se trata de un breve volumen de poesía "motivada" y "mimética", que funciona como un repertorio de "diagramatismos". Consta de un "Prólogo para Hermógenes", cuatro secciones que suman un total de 37 pocmas y unas "Notas" en las que se explican algunas de las "fórmulas" empleadas en los poemas. Un artículo interesante para ubicar el volumen en la trayectoria de Schiavetta es el de Jan Baetens (1996). 


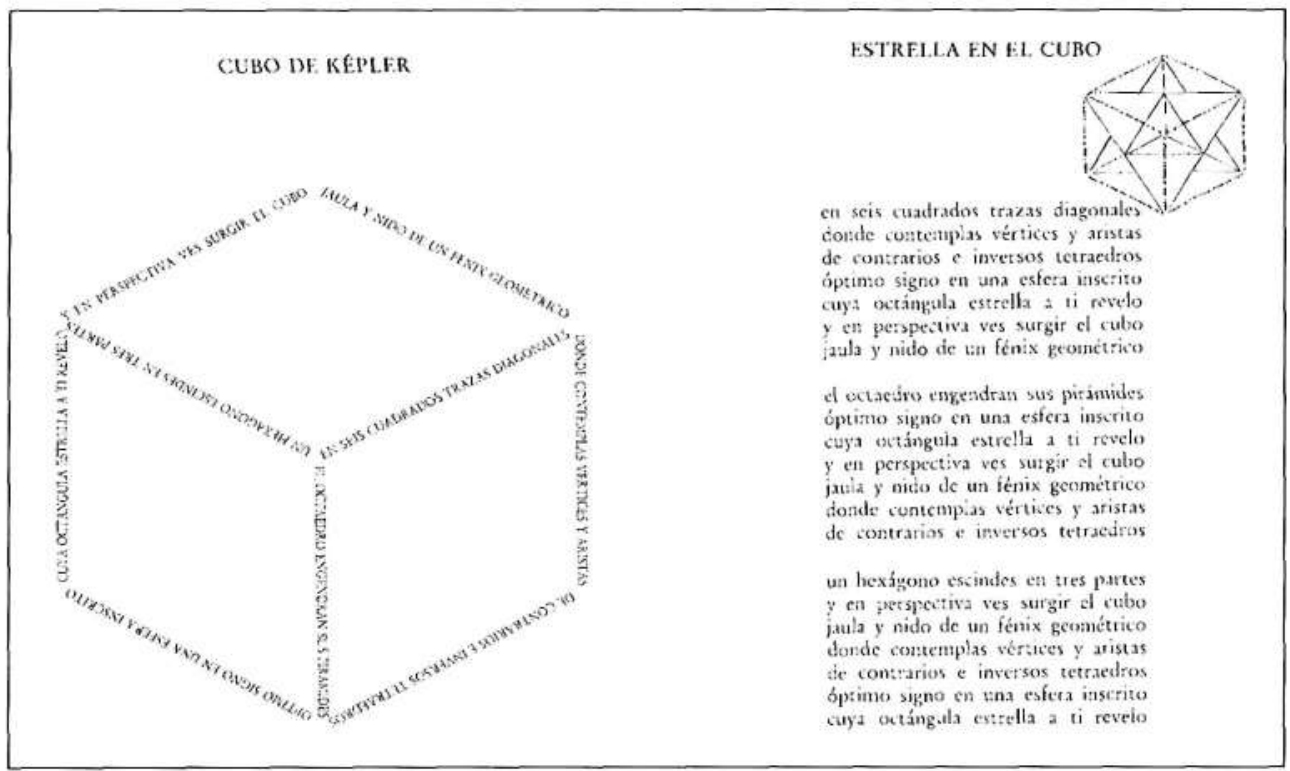

Fïg. 1: "Cubo de Képler" - "Estrella en el cubo"

El propio Bernardo Schiavetta define la "constricción" como «todo procedimiento productor de un texto» ${ }^{4}$. Tras reconocer su carácter "generalmente arbitrario» y eventualmente «absurdo» (lo que no implica una valoración necesariamente negativa), Schiavetta llega a proponer un concepto más refinado: el diagramatismo. Se trata de una constricción no arbitraria, motivada, a la que considera «un símbolo o un icono», «un signo con un significado inherente», definido -siguiendo a Pcirce-como: «un signo, en la materialidad del cual existe, de manera más o menos elaborada, una representación analógica o mimética del objeto, del referente significado por ese signo». La representación mimética constituye la motivación de dichos signos: «el texto significa su referente» ${ }^{6}$.

El concepto de "diagramatismo" es fundamental para entender cabalmente la forma del laberinto-poético, que el propio autor argentino practicará. Es significativo, por ejemplo, que a la

4.- Parafraseo en lo que sigue el artículo de Schiavetta (1992). Baetens (1996: 480) señala que Schiavetta prefiere el término de "matriz", por considerar "constricción" como algo connotado negativamente. Es útil la consulta de un artículo del propio Schiavetta (s. f.) sobre el tema, donde se lee: «a constraint is a systematic textual device that obeys the principle of specific saturation but which is not a norm in itself. Constraints are pseudo-norms".

5.- Detectada en la obra de Perec, uno de los principales oulipistas. Uno de los textos más conocidos de Perec, la novela lipogramática $L a$ disparition, es considerada un diagramatismo porque la ausencia de la letra $e$ se convierte en "icono de la desaparición". Otros ejemplos notables de diagramatismo son palíndromos de tema especular (que representan la simetría del espejo) o los "epitalamios" del mismo Perec, poemas que celebran la unión de parejas reales formados sólo por anagramas de los dos nombres de los celebrados.

6.- Advierte Schiavetta que conviene distinguir el "diagramatismo" de la "armonía imitativa" de la retórica tradicional (la aliteración o la paronomasia) en la medida en que esta última suele ser de carácter exclusivamente fónico y no abarca un texto completo. De igual forma, hay que distinguir el diagramatismo del Primer Principio Oulipiano, formulado por Jacques Roubaud: «Un texto escrito a partir de una contrainte habla de esa misma contrainte», que ya aparecería en casos de poemas metapoéticos ("Un soneto me manda hacer Violante...") y que, a juicio de Schiavetta, son sólo "autorrepresentaciones" de la constricción, sin llegar a su utilización simbólico-mimética. 


\section{DANIEL MESA GANCEDO}

hora de presentar algunos antecedentes del diagramatismo, Schiavetta remita a los technopaegnia o poemas figurados helenísticos (las Alas de Simias, la Siringa de Teócrito, menciona él; pero podríamos añadir el Hacha, también de Simias, un texto clave en el origen de la tradición del laberinto, a mi juicio $\left.{ }^{7}\right)$.

En el marco de reflexión diseñado por el problema de la motivación del signo y de la mimesis poćtica que podríamos considerar "exacerbada" hay que inscribir una obra como Fórmulas para Cratilo, de Schiavetta. Muchas de las ideas que expone en su trabajo sobre Perec se anticipan en el "Prólogo para Hermógenes" que abre el libro:

I as fórmulas compositivas de estos poemas (cuyo ancestro es la incomprendida Syrinx de Teócrito) intentan producir un efecto de significación clara y distinta, no sólo gracias a las palabras, sino gracias a la estructura material de sus ritmos. Estas fórmulas son, o deberían ser, perceptibles en la voz de quien las recita, más allá de la página y su disposición tipográfica. En eso difieren de los poemas "concretos" o "visuales". Cada poema, en su globalidad tipográfica y fónica, constituye un signo mimético (un ícono [sic] de Peirce). La significación inherente a ese signo es el tema mismo que las palabras del poema desarrollan, en conjunción idisociable de forma y sentido. (9)

En este fragmento, Schiavetta hace hincapié en la importancia del ritmo y su vínculo con el placer físico, así como la desviación explícita del contexto de la "poesía visual". Ello obedece, a mi juicio, a que se adopta ahí una perspectiva poiética -no exclusivamente tcórica o crítica-, lo cual pone en primer plano explícitamente también la importancia del "efecto de significación" por encima de lo que más tarde se convertirá en «efecto de "lectura" que va más allá de las palabras» (Schiavetta, 1992: 86): en la dialéctica entre esos dos efectos surge la mayor fucrza del diagramatismo, como veremos.

En el prólogo al libro, además, se hace cxplícita la conciencia de tradición que actúa sobre el poeta que escribe de este modo; pero incluso esa conciencia se integra perfectamente en el concepto de diagramatismo: «Estas fórmulas rítmicas no son, en sí, originales, sino que desarrollan, a veces hasta sus últimas consecuencias, formas ya existentes [...]. Adherir a una estética de la mímesis supone aceptar, desde cl principio, que se escribe para rehacer lo hecho» (10). El libro es en sí un diagramatismo: parece proponer artimañas retóricas para defender una concepción "cratiliana" del lenguaje, reforzada en el "Prólogo para Hermógenes" y explicitada en las notas finales. La alusión al Crátilo platónico supone la clave última que sostiene la concepción diagramática de la literatura que desarrolla Schiavetta tanto en la práctica como en la teoría. Las notas finales comienzan con una explicación de la explicación. En cierto modo, suponen una redundancia, una protección contra el riesgo de que el "efecto de lectura" no corresponda con el "efecto de significación" porque, como dice Schiavetta, las referencias «no necesariamente están en la memoria de todos» $(77)^{8}$. Quizá las notas son -en suma- la melancólica declaración de un fracaso: el texto no funciona por sí solo. Ni siquiera cl título es transparente "para todos" y se hace preciso explicar que Cratilo $[$ sic $]$ y Hermógenes son "figuras" en Platón para oponer

\footnotetext{
7.- Santarcangeli, en su opus magnum sobre el tema del laberinto apunta que para muchos autores el nombre del lugar podría provenir de labrys: "hacha de doble filo", "segur sacrificial" (Santarcangeli, 1984: 35-36), porque la figura del hacha aparece inscrita en muchos laberintos, como el de Creta. Santarcangeli no oculta que esa etimología es muy discutible para otros especialistas. No obstante, desde el punto de vista que ahora adopto, me parece interesante consignar el dato y señalar que nadie ha notado -hasta donde conozco- que sea también un "hacha doble" uno de los primeros ejemplos de laberinto poético: en efecto, el poema de Simias - a veces atribuido a Teócrito- no sólo "dibuja" un hacha, sino que obliga a una lectura "en espiral" - cfr. la explicación de su traductor al español (Martín García, 1994)-, movimiento laberíntico por excelencia.

8.- Como señala Baetens (1996: 481): «[...] il est impératif que les règles de l'écriture poétique puissent réellement être perçues [...]. Encore et surtout le lecteur doit-il sentir l'envie de prolonger les contraintes ou d'en chercher d'autres. Il faut en d'autres termes que les règles soient dotées d'une rentabilité psychologique, sans quoi l'cxercice de la littérature demeure l'apanage du seul auteur. Un texte ne doit pas seulemente être lisible, c'est-à-dire apte à susciter l'envie de lire, il doit aussi et surtout être lecturable, c'est-à-dire capable d'être compris au niveau de son agencement matériel» (según explica Baetens en nota, la distinción lisibilité (psicológica) / lecturabilité (técnica) procede de Jean Ricardou: "Élements de textique I", Conséquences, 10, 1989).
} 


\section{EL LUGAR Y LA FÓRMULA: “CUBO DE KÉPLER”, DE BERNARDO SCHIAVETTA}

la naturaleza mimética y la convencional del lenguaje. Schiavetta adhiere-como no podía ser de otra manera tras Saussure- a la tesis «sin duda exacta» de Hermógenes, aunque añade de inmediato: «Pero los poetas, decía Roland Barthes, optan siempre por el partido de Cratilo» (77).

Con ese punto de partida, el libro de Schiavetta deja de ser un mero divertimento, un «esfuerzo» sostenido, trasciende el «alarde formal [...] que ahoga todo efecto» ${ }^{9} \mathrm{y}$ se ofrece como investigación en el ser de la poesía y hasta del lenguaje mismo. En este libro, que es, finalmente, ejemplo, obra, diagramatismo, la apología de la motivación no es tan explícita como lo será tiempo después:

Se puede decir que en la obra de Perec, como en el caso de Teócrito y otros [el propio Schiavetta], la utilización mimética del procedimiento retórico resulta en una abolición de la arbitrariedad de la contrainte, pero también, lo que es mucho más importante, resulta en la abolición de la arbitrariedad del lenguaje. (1992: 86)

En efecto, de una lectura atenta del Crátilo platónico ${ }^{10}$ extraemos no sólo reflexiones sobre la condición "natural" o "convencional" del lenguaje sino dos consecuencias particularmente interesantes para mi propósito:

a) que el lenguaje (si no también la realidad) es un laberinto en cl que resulta sumamente difícil orientarse: la larga disquisición etimológica (falsa a menudo, según los helenistas) entre Sócrates y Hermógenes parece un esfuerzo (acaso paródico) por encontrar un "hilo" que permita dar sentido a la relación entre palabra y cosa;

b) que la concepción "motivada" del lenguaje privilegia las relaciones de semejanza entre palabra y cosa y, por lo tanto, la metáfora, propia de la poesía. La concepción "convencional" del lenguaje implica, entonces, que la relación entre palabra y cosa no es la de semejanza sino la de contigüidad; el régimen de la metonimia se enseñorea de la interpretación «sin duda exacta» del sentido del lenguaje, pero lo aparta del régimen poético. Pero hay más: si el lenguaje -como discurso-es semejante a un hilo, no sólo habrá que postular una contigüidad convencional entre palabra y cosa, sino una contigüidad necesaria entre uno y otro punto del discurso-recorrido (es la única relación que pueden mantener las palabras entre sí).

En esas circunstancias, la lectura de cualquier texto, pero especial y explícitamente de estos poemas de Schiavetta, se convierte - como señala Camarero- en «recorrido» y en «un acto de interpretación en sí mismo»" ${ }^{11}$.

El referente de las dos primeras partes del libro es el espejo: "Espejos del espejo" y "Otros espejos" son sus títulos. La mayor parte de los poemas, además, llevan la palabra "espejo" en su título y todos ellos representan el tema de la reproducción mediante recursos como el palíndromo en todas sus manifestaciones (léxico en el nivel del verso, o versal en el marco del poema, generando "poemas retrógrados" que pueden lecrse igual del principio al fin que del fin al principio) o incluso con la utilización exclusiva de "letras simétricas": AHIMOTUVXY. La tercera sección se títula "Círculos" y, en efecto, construye poemas "circulares", sin fin, del que la mejor muestra sería el títulado "Uróboro", dos cndecasílabos que se engarzan sin solución de continuidad (y, además, se imprimen representando un círculo en la página) y tematizan el efecto de lectura: «mis cabezas de hidra que renacen / con fauces de anfisbena que devoran». La última sección se titula "Otras fórmulas" y es mucho más distensa: encontramos poemas "segmentados" y "en cascada" para representar una "cabellera" o el fluir de las cosas; nuevos ejemplos especulares

9.- Suñén (1991). Y aun si fuera sólo "alarde" habría que relacionarlo con la "poética de la admiratio" legítimamente barroca (Cfr. Fernando R, de la Flor, 2000).

10.- Platón (1983).

11.- Camarero (1991: 164). Cfr. también Bactens (1996: 480): «[... l’effort de structuration textuelle aboutit à la découverte de principes d'écriture susceptibles de faire naître de nouveaux écrits et d'être exploités par d'autres que l'auteur même [...]». 


\section{DANIEL MESA GANCEDO}

con algunas variaciones; un poema "bustrófedon" así titulado (con letras simétricas); algún soneto aparentemente "tradicional" dedicado a San Juan de la Cruz; o, por fin, una diatriba monorrima contra "La poesía de los otros" que concluye: «desastrosa astrosa leprosa prosa».

En la última sección del libro, titulada "Otras fórmulas", encontramos un laberinto: el "Cubo de Képler" y lo que - en término tomado de la emblemática, dado que el "cubo" es un iconopodríamos llamar su declaración: "Estrella en el cubo". Conviene, en primer lugar, transcribir la nota explicativa que Schiavetta ofrece para, como mínimo, ratificar la conciencia de su relación con el género-forma del laberinto, además de para introducir "efectos de significación" que puedan orientar el "efecto de lectura":

Cubo de Képler: es la perspectiva de un cubo que se obtiene al dividir un hexágono en tres partes iguales. Képler describió la figura llamada Stella octangula (u octaedro estrellado) formada por los dos tetraedros estrecruzados [sic por "entrecruzados"] que están contenidos en el cubo. En el barroco español este tipo de poemas "visuales" se llamaban laberintos cúbicos. (83)

La relación del poema con la geometría ya está en no pocos caligramas vanguardistas, y será algo de lo que habrá que ocuparse siquiera mínimamente (así como de su relación con la astronomía, a través de la alusión a Képler). Pero antes hay que señalar que Schiavetta, al identificar «este tipo de poemas» con los «laberintos cúbicos» barrocos intensifica la motivación: aunque pueden encontrarse en el barroco algunos textos llamados «laberintos cúbicos» ${ }^{12}$, no he hallado ningún laberinto barroco que represente un cubo. Es cierto que "poema cúbico" (como señala Cózar, 1991, passim) era una designación común para algunos laberintos, aunque esa denominación apenas parecía aludir al hecho de que podían leerse en muchas direcciones, funcionando el adjetivo "cúbico" como una metonimia -a su vez- de una de por sí metafórica "tridimensionalidad" del texto. Schiavetta, sin embargo, construye un "poema cúbico" que representa a su vez un cubo, al tiempo que habla de la propia construcción del cubo (y de otros cuerpos geométricos) y por lo tanto genera un diagramatismo que, ahora sí con toda propiedad, puede llamarse "laberinto cúbico". La lectura de este texto, puede realizarse en tres momentos: mostración / descripción / interpretación-proyección.

\section{a) Mostración: la figura}

Lo primero que se impone en el acercamiento al "Cubo de Képler" es la imagen de la proyección de un hexaedro o cubo, conseguido, como aclaraba Schiavetta en la nota, por la división de un hexágono regular en tres partes iguales (que son rombos); o dicho de otro modo: por el trazado de tres radios de idéntico arco en la circunferencia en la que se inscribe dicho hexágono.

Sin querer entrar en las complejas relaciones entre matemática y poesía (algo casi por completo ajeno a mi competencia ${ }^{13}$, me parece oportuno, no obstante, señalar algunas cuestiones. En primer lugar, antes de leer nada, hay que asumir que el cubo representado por ese procedimiento -como cualquier representación de un cuerpo tridimensional en el plano-es un simulacro, que juega con las leyes de la perspectiva (en este caso de modo riguroso, pues sólo desde un único punto de vista - alineado con el centro de dicha circunferencia imaginaria y con el punto de fuga- pueden percibirse tres caras exactamente iguales en un hexaedro) ${ }^{14}$.

12.- He encontrado uno anónimo portugués en Kern (1999: 354), cuyo texto reza: «Entrai Joze Triunfante / dista machina Athlante», dedicado a honrar a D. Fr. Jozé M. ${ }^{\text {a }}$ de Évora.

13.- Un poeta y crítico argentino tiene un libro sobre el asunto, que no he podido ver: Arturo Cambours Ocampo: Poesía y matemática: indagación preliminar sobre el tema, Buenos Aires, Ediciones Marymar, 1990.

14.- Dicha exacerbación de la perspectiva pucde considerarse un juego manierista previo a la transgresión de sus leyes que operará el barroco, como señala R. de la Flor (2002: 336), y que influirá en la transgresión de la lectura lineal, al potenciar un «discurso de la mirada [que] produce la rotura de la fascinación por la norma lineal de la escritura, en una muestra más de la quiebra de las linealidades y convenciones de perspectiva en que se funda una estética barroca, según acredita la interpretación wolffinniana». 


\section{EL LUGAR Y LA FÓRMULA: “CUBO DE KÉPLER”, DE BERNARDO SCHIAVETTA}

En segundo lugar, la mención del matemático y astrónomo alemán en el título no sólo da la clave para identificar la constricción que genera este texto ${ }^{15}$ sino que, subsidiariamente, lo integra en una tradición (neo)platónica que identifica el cosmos con el poema, a través de la armonía de las $\operatorname{csferas}^{16}$. De ese modo el texto se convicrte en un elemento clave de la disquisición platónica que se despliega en Fórmulas para Cratilo. No estará de más recordar que el nombre de Képler aparece en Barroco de Sarduy como emblema del cambio del paradigma clásico-circular (representado en Galileo) al barroco-elipsoidal (elíptico) ${ }^{17}$. Surge, entonces, para lo posterior como nombre de una poética geométrica y (neo)barroca ${ }^{18}$, que es la que sin duda rige la producción de Schiavetta.

\section{b) Descripción: las formas de la fórmula}

Una vez asumida la simulación icónica que ofrece el poema, es necesario recorrerlo u operar con él. Sin el concurso de la declaración anexa, tendríamos problemas a la hora de decidir por dónde comenzar: podríamos hacerlo por el centro o por uno cualquiera de los "vértices" de la figura (pero enseguida caeríamos en la cuenta de que el centro es -visto tridimensionalmente- otro vértice). De tomar esta última opción, nos preguntaríamos por cuál empezar.

Parece lógico excluir aquellos versos que comienzan (o vértices ocupados) por un pronombre relativo («donde...» y «cuya...»), por una conjunción copulativa («Y...») o por una preposición («de...»), aunque estrictamente hablando sólo el verso que comienza por «cuya...» se vería privado por la sintaxis de una posible posición inicial absoluta, mientras que los demás, a priori, podrían postular un eventual hipérbaton o un sobreentendido. Sea como fuere, excluidas las cuatro posibilidades más controvertidas, nos encontraríamos con un poema circular (un bustrófedon) sin núcleo semántico (sin verbo principal) o con un núcleo elidido (y elipsis/elipse era el signo kepleriano-barroco según Sarduy) que permitiría leer dos poemas de seis versos que empezarán: [He aquí / Esto es] «Jaula y nido...» // «Óptimo signo...», justamente los dos versos opuestos

15.- Parece sugerirse que la transformación de hexágono en (fingido) hexaedro mediante la adición de tres radios distribuidos equitativamente sería un descubrimiento de Képler, que no he podido corroborar. Otra posibilidad, más compleja, es la sugerencia de que el "cubo de Képler" no se refiera al mecanismo de transformación, sino al cubo vacio y abierto utilizado por Képler en sus representaciones cosmológicas, lo cual tendría nuevas connotaciones en la interpretación del poema, como intentaré mostrar.

16.- Cualquier enciclopedia nos informa de que Képler defendía la teoría de las relaciones armónicas y musicales entre los cuerpos celestes. Más interesante todavía me parece poder situar en esa línea que va de Platón a Képler pasando por Plotino la modificación barroca que introduce el jesuita Nieremberg cuando afirma: «Plotino llamó al mundo poesía de Dios. Yo añado que este poema es como un laberinto, que por todas partes se lee y haze sentido y dicta a su Autor [Curiosa y oculta filosofía, Madrid, 1633] (apud R. de la Flor, 2002: 349). También lo recuerda Santarcangeli (1984: 187), quien señala que, para explicar su concepción, Nieremberg aludía a las technopaegniae helenísticas y consideraba que «scrivere dei labirinti vuol dire creare delle relazioni inestricabili e trasportare il lettore in sfere magiche».

17.- Barroco, 1974 (en Sarduy, 1999: 1197-1261). Képler, además, practica el "efecto de significación" no lineal, "jugando" a los anagramas con Galileo, en un episodio ampliamente narrado por Serra (2000: 113), quien afirma que, aunque no nombre a Képler, Monterroso (1987: 18) se reficre a este mismo episodio.

18. - Al respecto, conviene recordar alguno de los "elementos para una semiología del barroco latinoamericano" señalados por Sarduy: “Gramas fonéticos. En el mismo nivel que las letras que instauran un sentido en el recorrido lineal, fijado, "normal" de la página, pero formando otras posibles constelaciones de sentido, prestas a entregarse a otras lecturas, a otros desciframientos, a dejar oír sus voces a quien quiera escucharlas, existen otras posibles organizaciones de esas letras. Las líneas tipográficas, paralelas y regulares -determinadas por nuestro sentido lineal del tiempo-, a quien quiera transgredirlo, ofrecen sus fonemas a otras lecturas radiales, dispersas, fluctuantes, galácticas: lectura de gramas fonéticos cuya práctica ideal es el anagrama, operación por excelencia del escondite onomástico, de la sátira solapada y adivinable al iniciado, de la risa destinada al hermeneuta; pero también el caligrama, el acróstico, el bustrofedón y todas las formas verbales y gráficas de la anamorfosis, de los dobles e incompatibles puntos de vista, del cubismo; formas cuya práctica engañosa sería la aliteración." (El barroco y el neobarroco, 1972; en Sarduy, 1999: 1398). 


\section{DANIEL MESA GANCEDO}

paralelamente (hay que notar ya que el tercer verso "paralelo" a éstos es el único que nombra al objeto generador: "Un hexágono...». Esta lectura "circular" (y bidimensional) deja un resto sobrante de tres versos: los tres que, justamente, permiten simular el hexaedro, la figura tridimensional.

La lectura que comience por el centro ofrece tres posibilidades distintas, que son las insinuadas-corroboradas por la declaración, "Estrella en el cubo". Cada una comienza por uno de los versos centrales y prosigue "circularmente" por el perímetro del hexágono o las aristas del hexaedro, hasta volver a encontrarse con el final del primer verso. Cabe señalar ya que cualquiera de estas tres lecturas es la cabal representación del movimiento centrípeto en el interior de un laberinto, cuyo recorrido se produce en giros angulares y que -simuladamente- obliga a cambiar no sólo de dirección en el plano, sino también en el espacio.

Cada una de esas tres lecturas posibles tiene siete versos: uno de los centrales más los seis "perimetrales", en orden distinto cada vez y sin crisis sintáctica en ningún momento, puesto que cada verso central lleva un verbo principal. Podríamos decir que nos encontramos con un laberinto que permite tres recorridos por un mismo camino, que sólo difiere en el primer tramo y en la "salida" (aunque también podría decirse que las "salidas" sólo son tales en cada lectura concreta).

Sería interesante, además, que nos preguntáramos si cada una de las lecturas posibles del cubo forma en la "Estrella" un poema independiente de siete versos o una estrofa de un poema de veintiuno. Obviamente, tendríamos también que preguntarnos por la razón del orden en que aparecen esas tres estrofas-poemas.

Ello obliga a dedicar cierta atención a la "Estrella en el cubo" en sí misma. Es evidente que su disposición impone un orden que parece corresponder con el orden espacial-natural. O, más bien, convencional, en el sentido de la lectura occidental: la primera estrofa (el primer pocma) es la que surge de leer primero el verso central más próximo a la orientación horizontal izquierda-derecha («En seis cuadrados...») y las siguientes son las que siguen el mismo vector (es decir, se continúa "en el sentido de las agujas del reloj”). Pero ese orden "lógico" conculca, a poco que lo pensemos, el orden geométrico, pues al afirmar la existencia apriorística de "seis cuadrados", da por supuesta la existencia del "hexaedro", algo evidente en la presentación solidaria con el "cubo de Képler" en la página de la izquierda, pero que en el hilo del discurso sólo puede aceptarse conceptualmente después de la tercera estrofa: aquella en la que empieza a dibujarse el fingido hexaedro: «Un hexágono escindes en tres partes».

En medio de esas dos lecturas surgen varias figuras fantasmales, no dibujadas por el texto sino sólo, podríamos decir, citadas icónicamente -también por su disposición- como una especie de nota al título o al primer verso de "Estrella": «El octaedro engendran sus pirámides». Si de la contemplación del "Cubo de Képler" podíamos inferir la existencia simultánea (pero no en el mismo universo; o no en un universo de las mismas dimensiones) de un hexágono y de un cubo, nada en el icono inicial muestra pirámides, estrella u octaedro alguno. Éstos sólo surgen icónicamente como un excolio enigmático entre el título y el poema "Estrella", y textual y conceptualmente sólo cobran existencia en la lectura. Conviene ahora recordar que según la nota final de Schiavetta, la stella octangula es la que surge del resultado de intersecar dos tetraedros regulares (Fig. 2).

El autor afirma que Kepler describió ese cuerpo geométrico (como puede verse en sus representaciones cosmológicas), pero lo que no dice es que las aristas de esa estrella coinciden con las diagonales de las caras del hexaedro imaginario en que podría inscribirse y sus vértices son los mismos a los de éste, algo fundamental para entender sus versos. Tampoco nos dice que en el cruce de esos dos tetraedros regulares se construye, en su interior, un octaedro regular. 


\section{EL LUGAR Y LA FÓRMULA: “CUBO DE KÉPLER”, DE BERNARDO SCHIAVETTA}

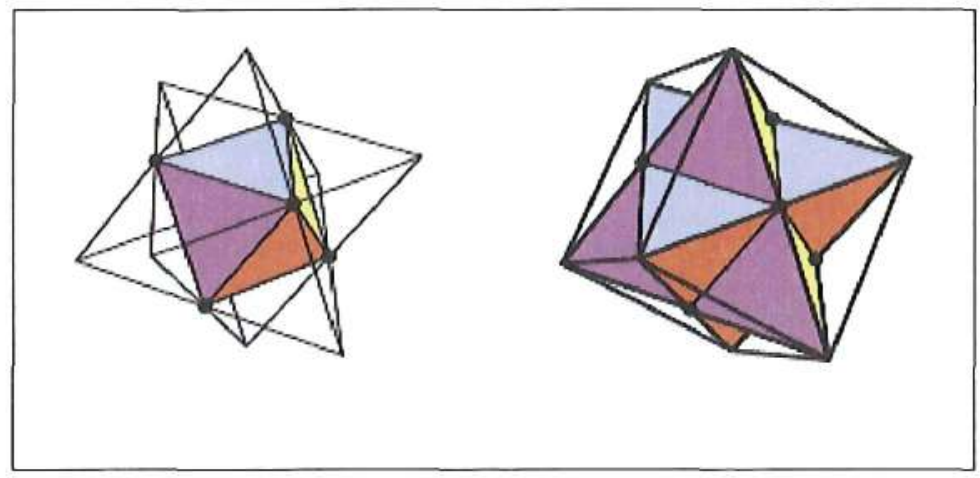

Fig. 2: Stella octangula - Octaedro en la estrella

Podemos decir que "Estrella" -como declaración-explicita y ordena los pasos que han podido darse en la lectura múltiple del "Cubo", ratificando en una secuencia completa lo que allí puede pasar como tres recorridos aislados. El icono alude a su propia construcción («Un hexágono...»); en segundo lugar (contra la tendencia de lectura convencional), invita a otra operación («En scis cuadrados trazas diagonales») que no deja huella escrita pero que anuncia la existencia de otras figuras posibles en el interior del cubo, la cual por fin se revela: la estrella octángula y, más adentro todavía, cl octaedro.

En resumen, podría decirse que: a) el "Cubo de Képler" da simultáneamente una multiplicidad de lecturas; b) que finge privilegiar un orden convencional horizontalvertical / izquierda-derecha, análogo al de la escritura-lectura occidental, opción que la "declaración" -"Estrella en el cubo"- afianza o ratifica, inscribiéndola; c) que el orden lineal de este poema total que propone la "Estrella" conculca el orden lógico de surgimiento de las figuras (tal como además se explicita en la nota final): presupone la existencia del hexaedro, insinúa la de otras figuras y sólo al final muestra el hexágono originario; d) que aparentemente la "declaración" constituye la lectura total del poema, porque es el único modo de leer los nueve versos distintos de que éste consta; e) que la "Estrella" revela la existencia en el interior del cubo de otras figuras que podrían no leerse en alguna de las lecturas parciales.

Pero también podría interpretarse que cada estrofa es un texto independiente en la que sc producen tres recorridos-desarrollos-procesos distintos, siempre de carácter epifánico (como veremos al analizar el contenido semántico de los versos). En este caso, se impone analizar las variantes e invariantes: es significativo que la sintaxis establece relaciones de contigüidad distintas en cada caso, obviamente. Así, por ejemplo, dado que la variable la constituye siempre el primer verso de cada estrofa, podemos fijarnos en cómo afecta al verso segundo, que se repetirá en todas ellas:

a) la "contemplación" que anuncia el de la estrofa 1, remite a las "diagonales" trazadas en los cuadrados; mientras que en la 2 y 3 remite al "fénix geométrico" o bien "al cubo";

b) el "óptimo signo" se refiere en la estrofa 2 a "el octaedro"; en la 1 a "contrarios e inversos tetraedros"; y en la 3, plausiblemente a "cubo";

c) la "perspectiva" que en la estrofa 3 genera el cubo a partir del hexágono escindido, en 


\section{DANIEL MESA GANCEDO}

la 1 se produce después de que se hayan trazado diagonales o después de que en la 2 se haya engendrado el "octaedro" y en ambos casos después de que se haya revelado la "estrella".

Podríamos concluir, además, que para cada estrofa-poema los dos versos elididos constituyen cl "significado oculto", necesario para la plenitud semántica del poema, pero imposible de decir en cada lectura individual.

\section{c) Interpretación-proyección: el sentido}

Pero el juego de lectura-recorrido puede proyectarse mucho más lejos. Sin ánimo de agotar todas las posibilidades, en la conciencia, quizá, de que es imposible salir de éste laberinto, expongo a continuación algunas cuestiones que evoca el texto.

\section{c. 1) ¿Por qué cada poema-estrofa tiene siete versos?}

Al margen del posible significado mágico del 7 y su frecuencia en la construcción de laberintos (cfr. Santarcangeli), esta cuestión, para el caso de un laberinto poético, está necesariamente relacionada con otra: ¿qué figura dibuja la lectura continua? Hay que darse cuenta de que el "cubo de Képler" -el hexágono dividido por tres radios- no puede dibujarse-trazarse de una sola vez, sin levantar el lápiz y sin pasar dos veces por el mismo lugar. Análogamente, no puede trazarse un dibujo-texto continuo de nueve líneas-versos con la disposición que ofrece aquí Schiavetta. Para conseguir dibujar el "hexaedro" de un solo trazo, partiendo de cualquier vértice o del centro, es obligatorio trazar diagonales en las "caras" (al menos una y como máximo tres, si no me equivoco): entonces cmpieza a surgir la estrella (la stella octangula), que sin embargo sólo se revela parcialmente.

Prescindiendo de las diagonales de las caras (como ocurre en el "Cubo de Képler"), se pueden trazar de una vez, a lo sumo, ocho líneas-versos. Pero para ello es obligatorio no partir del centro, sino de otro vértice. Si del dibujo pasamos a la escritura-lectura, ello obligaría a que uno o dos de los versos "centrales" estuvieran escritos en otro sentido: hacia el centro -pero sin detenerse en él-y no desde el centro, con lo cual la armonía (cl sentido) del laberinto quedaría rota.

Por otro lado, dibujo y escritura no son estrictamente análogos: el dibujo puede trazarse en ambos sentidos (izquierda-derecha / derecha-izquierda), mientras que la lectura (occidental) sólo puede trazarse de izquierda a derecha, y tal es el vector que, a priori, se impone incluso en este texto. Por ello, si se piensa en manipular la "rotación" del texto, habría que cambiar también la orientación en el plano de los versos "perimetrales" (operación que obligaría a de-construir y reconstruir físicamente el pseudo-cubo), generando una especie de in-cubo, o "demonio que posee al cubo" si vale el juego de palabras, (Fig. 3), lo que pondría a prueba la sintaxis (con éxito, puede anticiparse) y haría surgir otro texto múltiple y distinto (re-verso) de la "Estrella en el cubo", acaso un imposible "cubo en la estrella".

Si no se cambia la orientación en el plano de los versos "perimetrales", la hipótesis del comienzo "centrípeto" (en un vértice distinto del centro, pero que pasa por éste) generaría los siguientes textos posibles (pero no homogéneos):

a) Con dos comienzos "centrípctos":

- dos poemas "excéntricos" de ocho versos, cuyos sicte últimos serían idénticos

- uno de siete "centrado" y que recorre todo el perímetro (idéntico a los siete últimos del anterior)

- seis poemas periféricos o circulares de seis versos (comenzando cada uno por uno distinto -con los mismos problemas sintácticos evocados anteriormente-) 


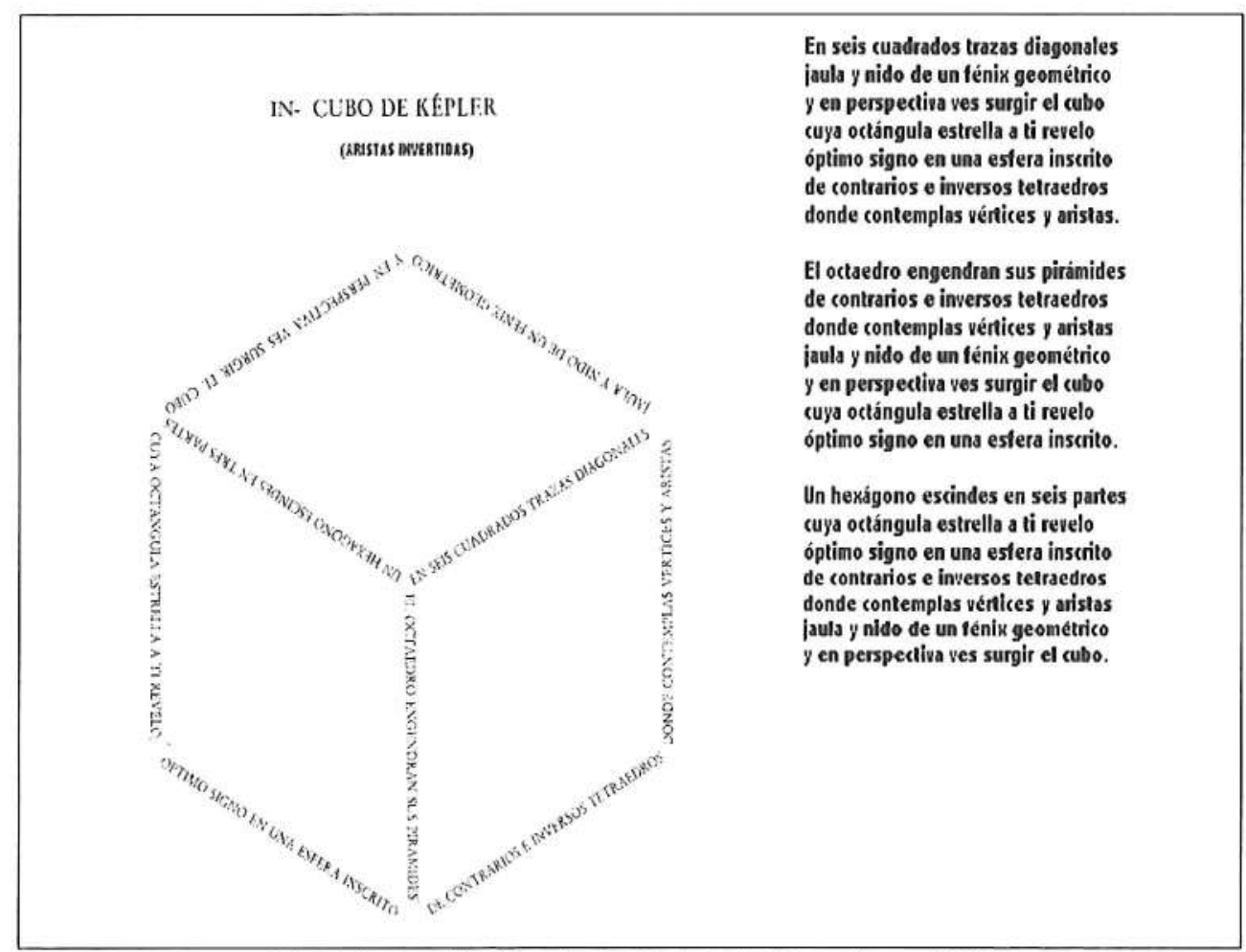

Fig. 3: (Per)versión: "In-cubo de Képler" - "¿Cubo en la estrella?"

- un uróboros o poema continuo (periférico)

b) Si hay un solo comienzo centrípeto:

- un poema excéntrico de ocho versos

- dos poemas centrados de siete versos: uno de ellos coincide con los siete últimos del anterior; el otro contiene seis pero en distinto orden.

- seis poemas periféricos de seis versos (comenzando cada uno por uno distinto)

- un uróboros o poema continuo (periférico)

c) La posibilidad de que haya tres comienzos centrípetos no deriva de la exigencia del dibujo más amplio posible de un solo trazo: no hay poema pues no hay continuidad posible (impedida por confluir los tres versos en el centro) o sólo

- tres poemas de un sólo verso (los centrales)

- seis poemas periféricos de seis versos (comenzando cada uno por uno distinto)

- un uróboros o poema continuo

d) Excolio: Si se cambia la orientación en el plano de los versos perimetrales, el número de poemas posibles se duplica. 


\section{DANIEL MESA GANCEDO}

Ello nos hace concluir que, partiendo del centro, la figura que puede dibujarse tiene como máximo siete líncas, esto es, el poema-estrofa sólo tiene siete versos y coincide con una lectura centrífuga continua, lo que da lugar al texto que tenemos: "Estrella en el cubo", que podemos describir como sigue:

a) Tres poemas-estrofas (centrados-centrífugos) de siete versos, seis de los cuales son comunes a los tres, pero en diferente orden.

b) Los tres versos centrales parten de un centro de divergencia (¿son di-versos?) y sintácticamente, de hecho, no se pueden subordinar, sino sólo yuxtaponer.

c) Es importante, también, darse cuenta de que, con esta disposición de los versos, no se pueden hacer lecturas "cerradas" de cuatro versos (romboidales): el texto queda literalmente abierto.

d) No se explota en este caso la combinación "perimetral", que daría el mismo resultado que en hipótesis anteriores

- Seis poemas de scis versos (comenzando cada uno por uno distinto)

- Un uróboros o poema continuo

El dibujo-texto-estrofa traza, pues, una figura de siete líneas que parte de un centro y rota hacia la derecha, en cl sentido de las agujas del reloj, simulando quizá una falsa espiral, símbolo que, como sabemos desde Santarcangeli, está estrechamente rclacionado con el laberinto. Aunque las lecturas reales (de siete versos), trazan un hexágono, y por tanto un recorrido aparentemente cerrado, es preciso señalar que ninguna de esas lecturas termina donde empezó, por lo que en cierto modo podríamos hablar-otra vez-de un texto "abierto".

El orden de los versos repetidos en cada estrofa sigue un patrón aritmético $(e 2=\mathrm{el}[\mathrm{x}+2+2+2+2$ $4-4] ; \mathrm{e} 3=\mathrm{e} 2[\mathrm{x}+2+2-4-4+2+2]$, donde $\mathrm{x}$ es el verso central generador $\mathrm{y}+/$ - indican el número de posiciones alteradas en los versos repetidos) que de aplicarlo a una hipotética cuarta estrofa ésta sería igual a la primera $(* \mathrm{e} 4=\mathrm{e} 3[\mathrm{x}-4-4+2+2+2+2]=\mathrm{e} 1)$, con lo cual quedaría cerrado, eventual pero imposiblemente el círculo. El poema sería una especie de fénix que resurge de sus cenizas, si no geométrico, como el aludido en el texto (y al que habrá que volver), "aritmético".

Por fin la lectura continua (uróboros) o las seis lecturas "cerradas" posibles (empezando por cada uno de los versos perimetrales) encierran (como «jaula o nido») a ese «fénix geométrico», que acaso es la que podríamos llamar "triada generadora". Metafóricamente, el poema total surge como "torbellino de aspas" $19 \mathrm{de}$ esa triada central que da lugar al texto circular.

\section{c. 2) ¿En qué plano está escrito cada verso presente?}

Ya vamos viendo cómo el laberinto pone en relación una presencia con una ausencia. En este caso, dada la simulación de la tridimensionalidad, es posible postular como "efecto de lectura" la existencia de un texto ausente u oculto, más allá de los versos no actualizados en cada lectura real.

La reflexión comienza aquí por una polisemia: tanto el verso como el lado del polígono o la arista del poliedro son líneas. Pero un verso no puede escribirse sobre una arista (pues la línea geométrica se desarrolla en un espacio de una dimensión: la longitudinal), mientras que la línea

19.- La imagen es creacionista, obviamente: el molino altazoriano. La fórmula exacta da título a un libro del vanguardista zaragozano Eugenio Frutos: Torbellino de aspas, ed. de Alberto Montaner y Enrique Serrano, Málaga, El Dormido en la Yerba, 1991. 


\section{EL LUGAR Y LA FÓRMULA: “CUBO DE KÉPLER”, DE BERNARDO SCHIAVETTA}

gráfica necesita de un espacio de dos dimensiones (alto-ancho). Queda así descubierta una primera falacia: el verso no es una arista.

Si en el texto-figura que nos ocupa parece en algún caso que el verso está sobre la arista («En seis...», «Un hexágono...», «El octaedro...»: o sea, los tres "generadores"), esto cs sólo apariencia, ficción, simulacro (¿mímesis?), puesto que en una representación realista se trataría de "aristas limadas", o como suele decirse: habría que matar los cantos (lo que abre un interesante doble sentido, que no recorreré por el momento). Pero la mera representación en perspectiva de los otros versos muestra que ellos no están escritos contando con esa ficción, sino que lo están en uno de los dos planos que confluyen en la arista. La perspectiva que afecta a la inscripción de esos versos hace pensar, a veces, que el hexaedro es hueco y cada plano tiene dos caras, la exterior y la interior, que también podemos ver, en algún caso, aunque no podamos decidir de cuál se trata (así por ejemplo: el verso "Jaula y nido...», ¿está en la cara superior externa o en la posterior derecha interna? Et sic de caeteris).

\section{c. 3) El texto ausente}

La figura parece invitar, sutilmente, al postulado de un texto ausente y a preguntarnos qué es lo que dicen los versos que no se ven (y, eventualmente, cuántos son éstos). Pensar que sólo dejamos de ver tres líneas-versos es una falacia lógica: si la lectura sólo se da (necesariamente) en un espacio bidimensional, esos tres versos-aristas no existen. Si consideramos un espacio tridimensional, teniendo en cuenta las observaciones del parágrafo anterior, faltarían muchos más de tres versos: quince (6x4-9, si sólo se considera una cara externa para cada "pared" del cubo) o treinta y nueve $(6 \times 2 \times 4-9$, si se considera la simulación de una cara interna y otra interna para cada "pared").

Puesto que, como hemos dicho, una arista es la intersección de dos planos, y el verso presente está escrito en uno sólo de ellos, en el otro plano (que no se ve) estaría escrito el re-verso. Si hay doce aristas en un hexaedro, cabe suponer la existencia, pues, de veinticuatro versos $(12 \times 2)$. Si sólo lecmos nueve, cabe preguntarse qué dicen los otros quince. De hecho podría pensarse que "Estrella" representa veintiuno de los veinticuatro versos posibles; entonces deberíamos preguntarnos qué ha ocurrido con los otros tres. Pero estas consideraciones se apoyan en la ficción de un espacio tridimensional, mientras que la lectura es imposible en ese espacio, ya que es puro "efecto", simulacro.

Eso queda demostrado porque algunos de esos versos ausentes deberían estar inscritos en caras "visibles" en la figura: los tres re-versos de los "generadores" (¿serían acaso éstos los tres versos "faltantes" en la "Estrella"?). Incluso cabría pensar que los veintiún versos de "Estrella" son la suma de los nueve distintos presentes y de los doce (¿repetidos?) que trazan las diagonales que definen la "estrella en el cubo". En cualquier caso, queda en evidencia la existencia de un "blanco-hueco" visible, otra manifestación de la opera aperta.

Por otro lado, hay que preguntarse también por la entidad de los vértices de esta figura. Si consideramos un espacio tridimensional, el vértice es el lugar donde coinciden tres aristas-planos; de ese modo, en el texto sólo tenemos falsos vértices. De hecho, éstos son, necesariamente, no homogéneos: en ellos confluyen dos aristas-versos y de ellos parte uno solo (podría pensarse que dos engendran -palabra inscrita en el texto- uno). Es imposible definir cada (pseudo-)vértice de este texto por unas coordenadas homogéneas en el espacio tridimensional (de tres elementos), ya que se perdería la información relativa al sentido-dirección de las líneas que lo definen. Llegamos así a una conclusión clave para el sentido de la lectura en general y de los laberintos en particular: para tener esa información relativa al sentido-dirección de la línea hace falta una 4." dimensión: el tiempo.

Así las cosas, creo que un texto como "Cubo de Képler" nos revela que la lectura se da un espacio de cuatro dimensiones (altura-anchura-[profundidad]-temporalidad), pero con elipsis (y aquí habría que acordarse de Sarduy) de una de ellas: la tercera, el volumen o la profundidad. 


\section{DANIEL MESA GANCEDO}

El espacio de la lectura es análogo pero distinto del espacio "real": se mueve en el plano y en el tiempo. El laberinto poético nos revela entonces que el sentido-metafóricamente-es el fondo que falta en la lectura. Ésta sólo revela una figura (forma o fórmula) y otro sentido del sentido.

\section{d) Conclusiones}

Por ello, quizá, podríamos dar por terminada esa lectura, sin necesidad de ir más allá, sin interpretar las palabras después de haber interpretado-recorrido el texto. La interpretación de las palabras es la tarea heroica: la de quien no querría retirarse sabiendo vedado el acceso a la cámara donde quizá espera el monstruo del sentido.

La "Estrella en el cubo" es probablemente el monstruo de este laberinto, el "fénix geométrico", inquietante por invisible. Como dije antes, aunque las palabras inscriben las "diagonales", "la estrella", el "octaedro", ninguna de estas figuras aparece dibujada: horribile visu? Tampoco aparece la esfera que envuelve el conjunto, con lo que acaso se confiesa la imposibilidad de representar la perfección (platónica). Pero, ¿qué pasaría si esas diagonales se escribieran-trazaran realmente? ¿Qué podrían decir? ¿Cuál es el mensaje de la estrella? ¿Cómo leerlo?

Que ese mensaje es hermético no ofrece la menor duda. La relación que se establece entre los sujetos intra-poéticos es casi de iniciación mística: un "yo" revela y un "tú" contempla y ve. El otro campo semántico capital es el del nacimiento-transformación: surgir, nido, cngendrar. La presencia del "fénix geométrico" es el punto de confluencia de toda esa significación simbólica: el objeto contemplado, único (y por tanto en relación con el Uno y la Perfección) y re-generado constantemente, como el mismo poema, según se vio. Y a la vez, como el poema mismo, simulacro, falsamente existente.

A tal respecto, es importante notar que incluso métricamente se procura individualizar el perfil de cada verso: todos son endecasílabos, pero casi todos llevan acentuación diferente ${ }^{20}$, en una combinatoria numérica que acaso tiene un sentido. El procedimiento combinatorio de los versos repetidos, por otro lado, tiene cierto parecido con los poemas paralelísticos de carácter sagrado o incluso con la sextina (practicada por Schiavetta en este mismo volumen, atribuyéndole una interpretación "espiraliforme" -1990a: 78- que la vincularía con el gesto engendrador del laberinto). En relación con el aspecto métrico, debe siquiera mencionarse el interesante juego de rimas: se notará la asonancia en "-áe" de los tres versos centrales y la asonancia en "-éo" de tres de los versos perimetrales: los que se imprimen en paralelo, pero en sentido inverso de escritura a los tres centrales. En ambas tríadas, por otro lado, aparece una palabra esdrújula (pirámides / geométrico). Al margen de cualquier interpretación concreta en el nivel léxico (que habría de incluir a la tríada "no marcada": inscrito-cubo-aristas), es evidente que ese doble paradigma intensifica (motiva) el juego combinatorio-aritmético que se describió más arriba.

En un nivel más profundo, la relación entre "efecto de significación" y "efecto de lectura" es análoga (y así lo representa este texto dúplice de Schiavetta) a la que mantienen -en la literatura emblemática- el icono y su declaración" ${ }^{21}$, como antes indiqué: el "cubo" es el icono (diagramatismo, en la terminología de Schiavetta) y la "estrella" es su despliegue-desarrollo. Son dos signos solidarios que se dan sentido recíprocamente, con la diferencia, respecto del emblema, de que cl icono, en este caso está trazado con palabras, es ya dibujo verbal, y la declaración es, en tal sentido, "redundante" o, si se prefiere, mímesis perfecta del icono. Lo que aporta la "estrella" es la plasmación explícita de la disposición de una lectura posible. La declaración no traduce lo que el icono sólo simboliza sino que actualiza en un espacio bidimensional (en una dirección de lectura tradicional y por lo tanto sucesiva) lo que el icono finge mostrar simultáneamente en tres

20.- Sólo «donde contemplas vértices y aristas» y «el octaedro engendran sus pirámides» coinciden en 4-6-10. Todos los demás son distintos.

21.- Cfr. R. de La Flor (2002: 341). 


\section{EL LUGAR Y LA FÓRMULA: “CUBO DE KÉPLER”, DE BERNARDO SCHIAVETTA}

dimensiones. Si invertimos el sentido de la explicación y leemos primero la "estrella", diremos -en términos adecuados a nuestros actuales intereses- que la declaración nos entrega el "hilo" que va a permitir salir del laberinto.

Estos dos textos o este texto gemelar se convierte en un espacio textual privilegiado para analizar las implicaciones del laberinto poético en una concepción no tradicional (y eventualmente revolucionaria) de la literatura. En primer lugar, hay que señalar que el laberinto poético, como todo artefacto textual que reclama una lectura no lineal exige -como, por otra parte, $\mathrm{cl}$ laberinto espacial- un ejercicio de memoria: recorrer el laberinto es recordar los espacios previamente atravesados para no repetir inútilmente algún paso. Rodríguez de la Flor ha señalado cómo el desarrollo de la poética tipográfica (en la que sin duda se inscriben los laberintos barrocos) favorece esa lectura no lineal y va de la mano con el desarrollo de las "artes de la memoria"22 y en términos más actuales (jakobsonianos) alude a que semejante lectura privilegia el eje de la selección sobre el de la combinación.

El texto laberíntico está sin terminar, es work in progress, leerlo es construirlo; el lector tiene los materiales y debe descubrir el "programa" para combinarlos. El laberinto es una fractura en el discurso compacto, que da los clementos ya combinados, y una exacerbación del principio que rige la función poética. Más que proyectar el eje de selección sobre el de combinación (Jakobson) -lo que convertiría a la combinación en necesaria (i. e. no arbitraria)-, el texto laberíntico obliga a un recorrido, revela que lo necesario es la selección, y, así, da lugar-quizá inesperadamente-a la epifanía de la libertad del lector. Esa libertad revelada provoca, acaso, la incomodidad o ansiedad de quien se enfrenta al texto laberíntico sin tener una imagen, un plano previo, que le marque el camino.

La poética del laberinto, pues, es una poética que -en términos retóricos clásicosentrega el ejercicio de la dispositio a la responsabilidad del lector y demuestra que aquél va intrínsecamente unido a los de la memoria y la actio: el laberinto exige operar (incluso físicamente, de donde puede derivar parte del placer físico que también -como prometía Schiavetta- ofrecen estos textos). El lugar del autor se limita a la inventio (por lo general, en los laberintos barrocos, de carácter áulico, sagrado o hermético; en Schiavetta: rígidamente diagramático, mimético, auto-referencial) y a la elocutio (en donde el aspecto métrico será fundamental como ocurre, por ejemplo, en el "Laberinto endecasílabo" de Sor Juana, y como Schiavetta se esfuerza por mantener).

La poética experimental - de la que el laberinto es probablemente un icono- constituye una función, según ha señalado Rodríguez de la Flor, siguiendo a Artaud, que cruza el "alarde solipsista" con el "riesgo exploratorio" (2002: 343) y, en tal sentido, el laberinto (lato sensu) representa su programa: la aventura de un sujeto aislado que decide (o al que no le queda más remedio que) explorar en lo enrevesado sin saber hacia dónde se dirige ni qué ha de encontrar al final del camino ${ }^{23}$. La poética experimental, entonces, manifiesta sus alcances transtextuales, bastante establecidos para otras épocas: en la medida en que conculca unos ciertos usos lingüísticos, en que no se conforma con el discurso establecido, el poema experimental (o la "extravagancia verbal") entabla relaciones conflictivas con el poder. Para el barroco y sus precedentes se ha identificado esta relación como de sometimiento y ello, justamente, por

22.- «Leer nemotécnicamente es trenzar y construir un espacio interior, donde la escritura adopta una suerte de polidimensionalidad que favorece el proceso de su somatización, al requerir del ojo un desplazamiento en profundidad por un campo virtualmente creado; aquel, precisamente, donde la imaginativa despliega sus fantasmas» (R. de la Flor, 2002: 339).

23.- Las implicaciones psicoanalíticas de esa aventura son especialmente interesantes en Schiavetta, teniendo en cuenta la importancia del tema del espejo en su obra y en Fórmulas... particularmente, así como el hecho de que profesionalmente el autor se desempeña en París como psicoanalista, si mis noticias son correctas. 


\section{DANIEL MESA GANCEDO}

su exacerbación de la motivación o la mímesis: Octaviano Porfirio salva su vida (cual nueva Scheherezade) regalando caligramas a Constantino (cfr. Cózar, 1991), lo que se ha interpretado como "servidumbre al sistema de valores establecido, afirmándose antes como lenguaje-espejo -como lengua de (l) poder- que como una posible lengua de la alteridad, abierta a lo no-conocido, a lo inefable e indecible" (Rodríguez de la Flor, 2002: 346). Las "extravagancias" verbales barrocas tenían una función áulica y monumental: se exhibían para admirar y, eventualmente, aterrar, como mecanismo de control.

Algo de eso puede afectar también al experimentalismo verbal post-moderno, trovar clus que confirma y conforma a ciertas élites. Pero no hay que descartar precipitadamente que en algún caso, tanto para el barroco como para lo post-moderno, surja la posibilidad de una "lengua de la alteridad" que, siquiera paródicamente (Porfirio contrarió la voluntad de Constantino, que quería matarlo), denuncia las falacias de la lengua de(l) $\operatorname{poder}^{24}$. Si, como dice Rodríguez de la Flor (2002: 346), "Le lieu c'est le message", cuando el mensaje es un laberinto el (genio del) lugar se complica $y$, parafraseando a Rimbaud, hay que concluir que le lieu est la formule ${ }^{25}$. Del peregrinaje barroco (recuérdese el inicio de la Soledad $I$ de Góngora) al vagabundeo postsimbolista, la escritura-lectura se convierte en laberinto, recorrido tortuoso, iluminada estadía en el infierno y en soledad confusa, tras la cual, a diferencia de lo que dice Dante y recuerda Santarcangeli ${ }^{26}$, tal vez ya no sea posible volver a «contemplar la estrella» o ésta sea-como revela Schiavetta- un puro efecto de lectura.

\section{BIBLIOGRAFÍA CONSUITADA}

ALTARRIBA, Antonio, ed. (1987): Sobre Literatura Potencial: Actas del Encuentro sobre Literatura Potencial, Vitoria, 2-6 diciembre, 1985. Vitoria, UPV.

BAETENS, Jan (1996): "Ecce poema: sur l'art poétique de Bernardo Schiavetta". Rivista di Letterature Moderne e Comparate, XLIX, pp. 479-490.

CAMARERO, Jesús (1991): "Fórmulas para Cratilo". Anthropos, 122/123, p. 164.

CARVALLO, Luis Alfonso de (1602): El Cisne de Apolo. Ed. de Alberto Porqueras Mayo. Kassel, Reichenberger, 1997.

CÓ7.AR, Rafael de (1991): Poesía e imagen. Formas difíciles de ingenio literario. Sevilla, El Carro de la Nieve. (http://boek861.com/lib_cozar).

KERN, Hermann (1999): Labyrinthe. München, Prestel (1.a ed.: 1982).

MARTÍN GARCÍA, José A. (ed.) (1994): Poesía helenística menor (poesía fragmentaria). Madrid, Gredos.

24.- Que Schiavetta no permanece ajeno a esa cuestión, siquiera sea por su (probable) condición de exiliado, lo manifiesta alguna declaración, a mi juicio, polémica, como aquella en la que afirma percibir cierto resentimiento entre los argentinos que "no pudieron o no se atrevieron" a salir del país en el momento de la dictadura (declaraciones a El País de Madrid, 14 de Agosto de 1990). Al margen de que unos y otros no obraron por las mismas motivaciones, el gesto de Schiavetta parece decididamente enfrentado a un discurso de la conmiseración.

25.- «J'avais en effet, en toute sincérité d'esprit, pris l'engagement de le rendre à son état primitif de fils du soleil, - et nous errions, nourris du vin des cavernes et du biscuit de la route, moi pressé de trouver le lieu et la formule» ("Vagabonds", Les illuminations; Rimbaud, 1984: 176).

26. «Nel laberinto - lo abbiamo già detto- si abolisce anche il tempo: è "tenebra sanza tempo tinta"; e ben lo sapeva il Poeta, quando entrò nelle viscere della Terra per compiere il grande viaggio. Solo importa che, al termine del cammino, si torni "a riveder le stelle". La conquista umana del sapere -il rinvenimento del Centro, del locus absconditus - è il solo approdo possibile e sensibile; è un uscire dalle tenebre; è la conquista della chiarezza dopo avere passato le acque infernali» (Santarcangeli, 1984: 246). 


\section{EL LUGAR Y LA FÓRMULA: “CUBO DE KÉPLER”, DE BERNARDO SCHIAVETTA}

MONTERROSO, Augusto (1987): La letra e. Madrid, Alianza.

PADÍN, Clemente (2001): La poesía experimental latinoamericana (1950-2000). Madrid, Información y producciones S.L., 2001 (http://boek861.com/padin/).

PLATÓN (1983): Crátilo, en Diálogos, vol. II (Gorgias, Menéxeno, Eutidemo, Menón, Crátilo). Trads. y eds. de J. Calonge Ruiz, E. Acosta Méndez, F. J. Olivieri, J. L. Calvo. Madrid, Gredos, pp. 339-461.

RIMBAUD, Arthur (1984): Poésies. París, Le Livre de Poche.

R[ODRÍGUEZ]. DE LA FLOR, Fernando (2002): Barroco. Representación e ideología en el mundo hispánico (1580-1680). Madrid, Cátedra.

SANTARCANGELI, Paolo (1984): Il libro dei labirinti. Storia di un mito e di un símbolo. Milán, Frasinelli.

— (1997): El libro de los laberintos. Trad. de César Palma. Madrid, Sirucla.

SARDUY, Severo (1999): Obras completas, vol. II. Madrid, Archivos-Galaxia Gutemberg.

SCHIAVETTA, Bernardo (1990a), Fórmulas para Cratilo. Madrid, Visor.

— (1990b): "Entrevista". El País, 14 de agosto.

— (1992): "Los diagramatismos de Georges Perec", Anthropos, 134-135, julio-agosto, 1992, pp. 85-86.

- (s. f.): "Toward a General Theory of the Constraint", Electronic book review, 10 (http:// www.altx.com/ebr/ebr10/10sch.htm).

SERRA, Màrius (2000): Verbalia. Juegos de palabras y esfuerzos del ingenio literario. Barcelona, Península-Atalaya.

SUÑÉN, Juan Carlos (1991): "Fórmulas para Cratilo". El País, 17 de marzo.

VV. AA. (2001): L'OULIPO: La littérature comme jeu. Magazine Littéraire, 398, mayo. 